\title{
Narrow Band Defect Luminescence from Al- doped ZnO Probed by Scanning Tunneling Cathodoluminescence
}

\section{Citation}

Likovich, Edward M., Rafael Jaramillo, Kasey J. Russell, Shriram Ramanathan, and Venkatesch Narayanamurti. 2011. Narrow band defect luminescence from Al-doped ZnO probed by scanning tunneling cathodoluminescence. Applied Physics Letters 99(15): 151910.

\section{Published Version}

doi:10.1063/1.3647622

\section{Permanent link}

http://nrs.harvard.edu/urn-3:HUL.InstRepos:5371009

\section{Terms of Use}

This article was downloaded from Harvard University's DASH repository, and is made available under the terms and conditions applicable to Open Access Policy Articles, as set forth at http:// nrs.harvard.edu/urn-3:HUL.InstRepos:dash.current.terms-of-use\#OAP

\section{Share Your Story}

The Harvard community has made this article openly available.

Please share how this access benefits you. Submit a story.

\section{Accessibility}




\section{AIP Appilate Prysises \\ Letters}

\section{Narrow band defect luminescence from Al-doped ZnO probed by scanning tunneling cathodoluminescence}

Edward M. Likovich, Rafael Jaramillo, Kasey J. Russell, Shriram Ramanathan, and Venkatesh Narayanamurti

Citation: Appl. Phys. Lett. 99, 151910 (2011); doi: 10.1063/1.3647622

View online: http://dx.doi.org/10.1063/1.3647622

View Table of Contents: http://apl.aip.org/resource/1/APPLAB/v99/i15

Published by the American Institute of Physics.

\section{Related Articles}

Effect of CdS film thickness on the photoexcited carrier lifetime of TiO2/CdS core-shell nanowires Appl. Phys. Lett. 99, 153111 (2011)

Current underestimation of the optical gap and Burstein-Moss shift in $\mathrm{CdO}$ thin films: A consequence of extended misuse of 2-versus-h plots

Appl. Phys. Lett. 99, 151907 (2011)

Wurtzite $\mathrm{ZnO}$ (001) films grown on cubic $\mathrm{MgO}$ (001) with bulk-like opto-electronic properties

Appl. Phys. Lett. 99, 141917 (2011)

Oxygen enhanced ferromagnetism in Cr-doped $\mathrm{ZnO}$ films

Appl. Phys. Lett. 99, 052513 (2011)

Highest transmittance and high-mobility amorphous indium gallium zinc oxide films on flexible substrate by roomtemperature deposition and post-deposition anneals

Appl. Phys. Lett. 99, 051901 (2011)

\section{Additional information on Appl. Phys. Lett.}

Journal Homepage: http://apl.aip.org/

Journal Information: http://apl.aip.org/about/about_the_journal

Top downloads: http://apl.aip.org/features/most_downloaded

Information for Authors: http://apl.aip.org/authors

\section{ADVERTISEMENT}

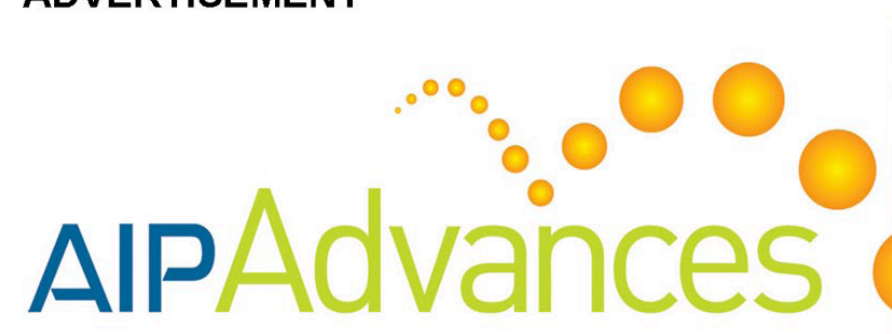

Submit Now

\section{Explore AIP's new \\ open-access journal}

Article-level metrics now available

Join the conversation!

Rate \& comment on articles 


\title{
Narrow band defect luminescence from Al-doped ZnO probed by scanning tunneling cathodoluminescence
}

\author{
Edward M. Likovich, ${ }^{\text {a) }}$ Rafael Jaramillo, Kasey J. Russell, Shriram Ramanathan, \\ and Venkatesh Narayanamurti \\ School of Engineering and Applied Sciences, Harvard University, Cambridge, Massachusetts 02138, USA
}

(Received 8 April 2011; accepted 10 September 2011; published online 12 October 2011)

\begin{abstract}
We present an investigation of optically active near-surface defects in sputtered Al-doped $\mathrm{ZnO}$ films using scanning tunneling microscope cathodoluminescence (STM-CL). STM-CL maps suggest that the optically active sites are distributed randomly across the surface and do not correlate with the granular topography. In stark contrast to photoluminescence results, STM-CL spectra show a series of sharp, discrete emissions that characterize the dominant optically active defect, which we propose is an oxygen vacancy. Our results highlight the ability of STM-CL to spectrally fingerprint individual defects and contribute to understanding the optical properties of near-surface defects in an important transparent conductor. (C) 2011 American Institute of Physics. [doi:10.1063/1.3647622]
\end{abstract}

\begin{abstract}
Aluminum-doped zinc oxide (AZO) exhibits similar electronic properties to $\mathrm{ZnO}$ : a wide optical band gap $\left(E_{g} \geq\right.$ $3.37 \mathrm{eV})$, a strong exciton binding energy $(60 \mathrm{meV})$, and optical transparency throughout the visible spectrum. ${ }^{1,2}$ Doping $\mathrm{ZnO}$ with $\mathrm{Al}$ increases the electrical conductivity by several orders of magnitude and the material is called a transparent conducting oxide (TCO). In order to best exploit AZO in device technologies, a thorough understanding of the role of defects and dopants in electron transport and light emission is required.

Here, we probe the surface of sputtered AZO films with nanometer resolution using scanning tunneling microscope cathodoluminescence (STM-CL). ${ }^{3,4}$ In our experiments, we inject high energy holes into the sample, and the resulting optical spectra are signatures of the optically active final states that these holes relax into before combining with electrons from the degenerately doped conduction band. Whereas photoluminescence (PL) probes a relatively large volume, the high spatial resolution of STM-CL allows individual defects to be spectrally identified, thus overcoming a significant impediment to understanding deep level photoemission in $\mathrm{ZnO}$ : namely, that the deep level PL spectra are broadband and integrate over many defect sites. ${ }^{5}$ This has confounded attempts to draw connections between calculated defect emission levels and experimentally measured PL spectra; ${ }^{5-8}$ e.g., the ongoing debate over the origin of the green PL band, which is in all likelihood has multiple sources. ${ }^{9}$
\end{abstract}

Our AZO thin films were grown on glass by RF magnetron sputtering from a $\mathrm{Zn}$ :Al $1.2 \mathrm{wt}$. \% target $(99.99 \%$, ACI Alloys, Inc.). The RF power, substrate heater temperature, Ar flow rate, $\mathrm{O}_{2}$ flow rate, and total process pressure were $100 \mathrm{~W}, 200{ }^{\circ} \mathrm{C}, 40 \mathrm{sccm}, 6.4 \mathrm{sccm}$, and $2.5 \mathrm{mTorr}$, respectively. The AZO films were measured by $\mathrm{x}$-ray reflectivity to be $60 \mathrm{~nm}$ thick. Optical transmission and absorption spectra were measured on a Hitachi U-4001 spectrophotometer with an integrating sphere, and from these measurements we estimate that the Fermi energy $\left(E_{F}\right)$ lies in the conduction band,

${ }^{\text {a)} E l e c t r o n i c ~ m a i l: ~ l i k o v i c h @ p o s t . h a r v a r d . e d u . ~}$ offset from the band edge by $E_{F}-E_{c} \sim 0.25 \mathrm{eV}$. Temperature dependent Hall measurements give n-type carrier concentrations of $7.4 \pm 0.2 \times 10^{20} \mathrm{~cm}^{-3}$ and mobilities of $17 \pm 1$ $\mathrm{cm}^{2} \mathrm{~V}^{-1} \mathrm{~s}^{-1}$ that are constant to within a few percent between $300 \mathrm{~K}$ and $4 \mathrm{~K}$.

The as-grown films were loaded into a home-built STM. Measurements consisted of grounding the etched tungsten tip and applying bias to the AZO film, such that negative bias corresponds to hole injection from the tip to the sample. We observed no luminescence for positive bias (electron injection), consistent with our understanding that luminescence results from radiative recombination of injected holes with electrons from the degenerately doped conduction band. Luminescence was collected by a lens mounted behind the sample and collinear with the tip. The lens coupled light into a fiber mounted outside the vacuum chamber that was connected to either an avalanche photodiode (APD, Perkin Elmer SPCM-AQR-14) or a spectrometer (Horiba Jobin Yvon iHR320). All measurements were conducted at room temperature and $\sim 10^{-8}$ Torr.

STM-CL spectra were recorded at biases ranging from -80 to $+80 \mathrm{~V}$, which is considered low energy for cathodoluminescence. It is known that the inelastic mean free path of energetic charge carriers depends strongly on energy in the range that we investigated. ${ }^{10}$ Typical inelastic mean free paths for energies of tens of $\mathrm{eV}$ are $1 \mathrm{~nm}$ or less. ${ }^{11}$ Studies of oxide materials report a monotonic decrease of inelastic mean free path up to $\sim 100 \mathrm{eV},{ }^{12}$ with a sharp decrease as energy exceeds the plasma excitation energy. ${ }^{13}$ Since the energy range that we investigate is above the plasma excitation energy in AZO, we conclude that our STM-CL measurements only probe the near-surface layers with energetic holes. Given that AZO is a degenerate n-type conductor and that the minority hole mobility is expected to be significantly lower than that for majority electrons, ${ }^{14}$ we assume that electron-hole recombination occurs within the inelastic penetration depth of the holes $(\sim 1 \mathrm{~nm})$.

Fig. 1(a) shows STM-CL topography $z(x, y)$ recorded by rastering the tip across the sample surface at $-30 \mathrm{~V}$ bias while adjusting the tip height $z$ to maintain constant current. 
The high bias inherent to STM-CL measurements results in poorer resolution than typical STM topography scans due to the significant tip-sample separation and beam spreading. However, the STM-CL topography data are sufficient to resolve grains and grain boundaries in AZO. Overlaid on this topography map are highlighted pixels which indicate optically active areas, as determined by luminescence collected concurrently with the topography using an APD. These centers, which we attribute to near-surface defects, appear to have no correlation with the surface topography (i.e., grains and grain boundaries). This suggests that optically active defects are distributed randomly across the film, and that the previously reported grain boundary electron traps are not optically active. ${ }^{15}$

We obtain spectral information on these defect centers by positioning the STM tip above an optically active site and coupling luminescence into a spectrometer. Fig. 1(b) shows a typical STM-CL spectrum recorded at $-80 \mathrm{~V}$ overlaid with photoluminescence recorded with $325 \mathrm{~nm}$ laser excitation. The most prominent difference between the PL and STM-CL spectra is the sharpness of the deep-level emission lines observed by STM-CL. This we attribute to the measured sample volume. Our STM-CL probes a volume of several $\mathrm{nm}^{3}$ at the surface, while PL (and typical CL well above $1 \mathrm{kV}$ ) probes the entire film (absorption coefficient $\alpha=0.007 / \mathrm{nm}$ at the excitation wavelength). We propose that the difference in linewidth results from the presence of a single predominant near-surface defect which is responsible for just a fraction of the PL spectra. This is supported by our observation (Fig. 1(b), inset) that the STM-CL spectra from dif-

(a)

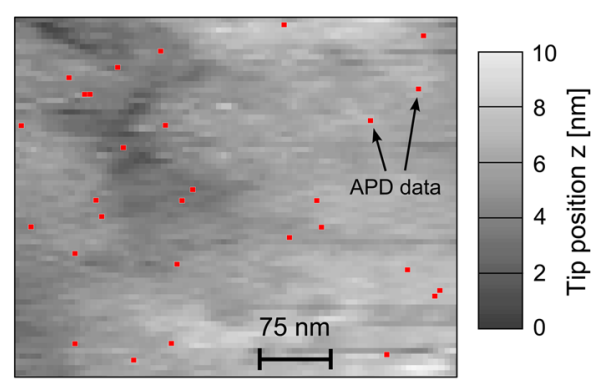

(b)

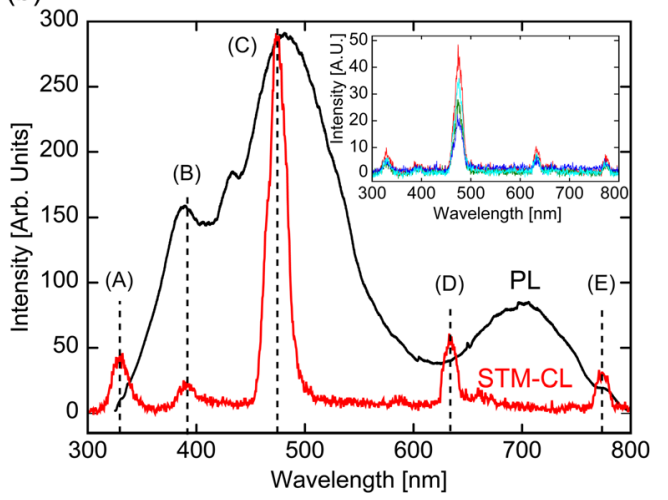

FIG. 1. (Color online) (a) STM-CL constant current topography map taken with $-30 \mathrm{~V}$ bias applied to the AZO sample relative to the tip. A grain boundary is evident as the dark crevice in the top left of the image. Overlaid on this are square pixels that represent optically active areas from measured APD luminescence data. This surface area defect density corresponds to $\sim 10^{10} \mathrm{~cm}^{-2}$. (b) Comparison of photoluminescence from $325 \mathrm{~nm}$ laser excitation (black) and STM-CL at $-80 \mathrm{~V}$ sample bias (red). (Inset) STM-CL spectra from a variety of sample locations taken at $-40 \mathrm{~V}$ sample bias. ferent optically active sites are nearly identical across the sample surface. This suggests that the two techniques, STMCL and PL, measure emission from two different populations of optically active defects. Possible mechanisms to explain this difference include a dependence of the defect emission energy on depth (e.g., due to strain effects), and defect sites optically excited by photo-generated electron hole pairs that do not interact strongly with high energy injected holes.

Despite years of sustained experimental and theoretical studies of deep level emission in doped and undoped $\mathrm{ZnO}$, assigning luminescence peaks to particular point defects remains complicated. ${ }^{5-8,16-20}$ Nevertheless, most authors agree on three points: ${ }^{6-9}$ for degenerately doped $\mathrm{ZnO}$ oxygen vacancies, $\mathrm{V}_{\mathrm{O}}$ are thermodynamically favorable; $\mathrm{V}_{\mathrm{O}}$ are deep donors, and for $\mathrm{n}$-type $\mathrm{ZnO}$ are the most stable in the neutral charge state $\mathrm{V}_{\mathrm{O}}^{x}$; and the charge states of $\mathrm{V}_{\mathrm{O}}\left(\mathrm{V}_{\mathrm{O}}^{x}\right.$, $\mathrm{V}_{\mathrm{O}}^{\bullet}$, and $\mathrm{V}_{\mathrm{O}}^{\bullet \bullet}$ ) are well separated within the band gap, due to a large ionic rearrangement around $\mathrm{V}_{\mathrm{O}}$ resulting in an effective negative- $U$ interaction between localized holes. Based on the consistency of our spectra from site-to-site, we assume that all the observed surface defects are of the same type, and due to the wide distribution of deep-level emission lines, we propose that our STM-CL spectra represent emission from individual $\mathrm{V}_{O}$ sites. Specifically, referring to the labels in Fig. 1(b), we attribute peaks C $(475 \mathrm{~nm}, 2.62 \mathrm{eV})$, D $(642 \mathrm{~nm}, 1.95 \mathrm{eV})$, and $\mathrm{E}(787 \mathrm{~nm}, 1.59 \mathrm{eV})$ to emission from different charge states of $V_{O}$. The strongest peak at $475 \mathrm{~nm}$ is consistent with the blue-green emission reported in $\mathrm{ZnO}$ and AZO films and most often attributed to oxygen vacancies, ${ }^{5,17-20}$ although the specific charge states of $V_{O}$ involved the question of whether an electron is captured from the conduction band or a hole from the valence band, or even of whether $\mathrm{V}_{O}$ at all contribute to the characteristic green luminescence remain unresolved issues in the literature. ${ }^{9}$ We attribute peak $\mathrm{A}(329 \mathrm{~nm}, 3.77 \mathrm{eV})$ to recombination of electrons at the Fermi level with holes from the valence band (peak A is strongly suppressed in PL due to a laser line filter); this is supported by optical absorption spectroscopy (not shown) which shows that the absorption edge in our films is close to $3.8 \mathrm{eV}$. We attribute peak B $(391 \mathrm{~nm}$, $3.18 \mathrm{eV}$ ) to donor-bound exciton recombination.

It is interesting to compare the measured density of optically active sites to published estimates for the concentration of $\mathrm{V}_{\mathrm{O}}$ in $\mathrm{ZnO}$. Assuming the injected holes penetrate $\sim 1 \mathrm{~nm}$ into the film, the measured area density of $\sim 10^{10} \mathrm{~cm}^{-2}$ (Fig. 1(a) corresponds to a concentration of $\sim 10^{17} \mathrm{~cm}^{-3}$. The concentration of $\mathrm{V}_{\mathrm{O}}$ in $\mathrm{ZnO}$ after high temperature annealing is reportedly $10^{18}-10^{19} \mathrm{~cm}^{-3}, 21,22$ although this should vary with annealing temperature and may be reduced at the sample surface. ${ }^{23}$ The similarity between our measured defect concentration and the reported values for $\mathrm{V}_{\mathrm{O}}$ in $\mathrm{ZnO}$ is encouraging. However, our system differs from the published reports in notable ways including sample stoichiometry, thermal history, and measurement protocol.

STM-CL spectra measured as a function of bias for constant current are shown in Fig. 2(a). We interpret the increase in intensity (i.e., increase in quantum efficiency) with larger negative bias according to the prevailing theoretical understanding that $\mathrm{V}_{\mathrm{O}}$ are negative- $U$ centers: due to a concurrent lattice distortion, the doubly charged $\mathrm{V}_{\mathrm{O}}^{\bullet \bullet}$ state is more stable 

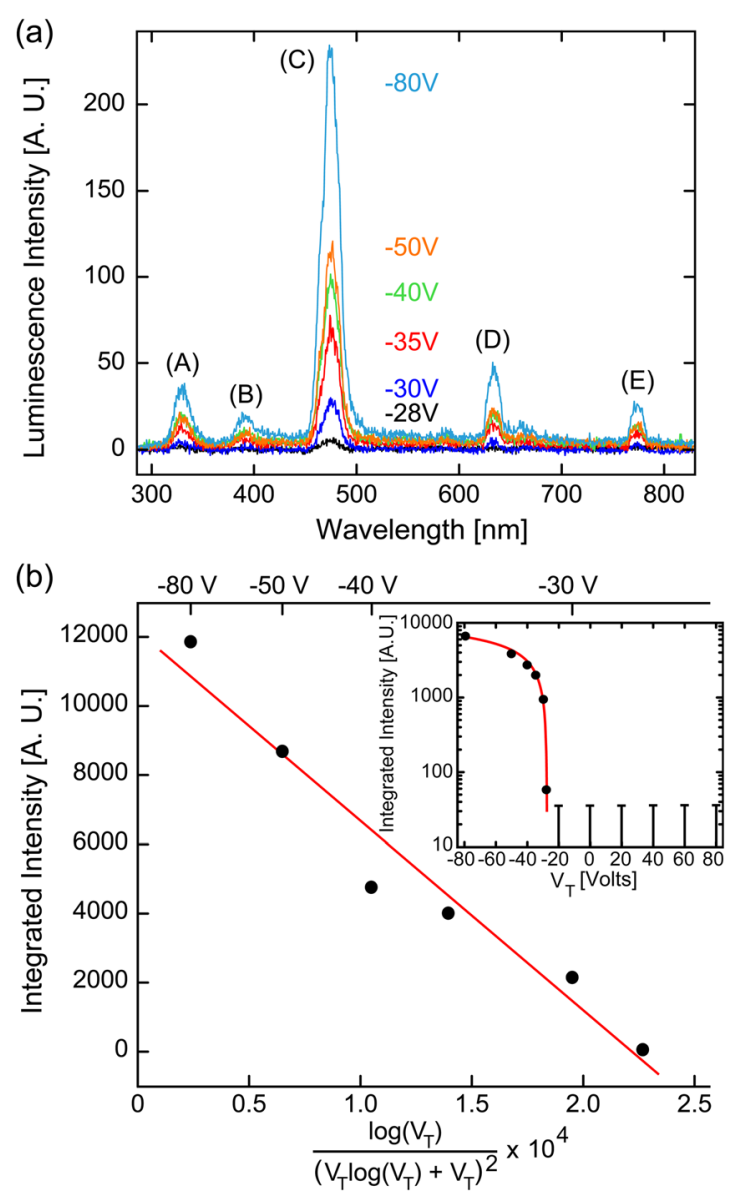

FIG. 2. (Color online) (a) STM-CL for sample biases, $V_{T}$, ranging from $-28 \mathrm{~V}$ to $-80 \mathrm{~V}$ with constant current $I=50 \mathrm{nA}$. The signal intensity increases with bias, which is quantified in (b) integrated intensity of the prominent STM-CL peak at $480 \mathrm{~nm}$ plotted against $\log \left(\left|V_{T}\right|\right) /\left(\left|V_{T}\right| \cdot \log \left(\left|V_{T}\right|\right)\right.$ $\left.+\left|V_{T}\right|\right)^{2}$. The linear relationship suggests that the emission quantum efficiency scales with local heating, consistent with a model of phonon assisted hole de-trapping. (Inset) Intensity data from (b) plotted against bias. The fit function from (b) is shown in red, and the sensitivity limit (at 1:1 signal:noise) of our null measurements for $V_{T}>-28 \mathrm{~V}$ are shown with error bars.

than $\mathrm{V}_{\mathrm{O}}^{\bullet}$ for all $E_{F},{ }^{6-8}$ and as a result $\mathrm{V}_{\mathrm{O}}$ are "hole killers." 6 Holes excited in n-type $\mathrm{ZnO}$ can become trapped in the metastable $\mathrm{V}_{\mathrm{O}}^{\bullet \bullet}$ state. In accordance with the Franck Condon principle, optical recombination of a hole trapped at a $\mathrm{V}_{\mathrm{O}}^{\bullet \bullet}$ site involves a lattice excitation that matches the original distortion. We propose that the increase in quantum efficiency at high bias is related to the expected minimum in inelastic mean free path for $E \sim 100 \mathrm{eV}$. As the volume of the sample illuminated by energetic holes decreases, the degree of local heating increases, thus providing a population of phonons that can de-trap the holes at the oxygen vacancies and promote radiative recombination.

We can quantify this model of phonon assisted detrapping using a simple model of intensity $\sim N_{p} / V$, where $N_{p}$ is the number of phonons generated and $V$ is the volume in which the hot holes relax in energy. By conservation of energy, we expect $N_{p} \sim V_{T}$, where $V_{T}$ is the applied voltage, which is directly related to energy of the injected holes $\left(q \cdot V_{T}\right) . V \sim A \cdot \lambda$, where $A$ is the effective beam area that scales as $A \sim\left(V_{T} \cdot \log \left(V_{T}\right)+V_{T}\right)^{2}$ from the Fowler-Nordheim field emission equation solved for constant current, ${ }^{24}$ and $\lambda$ is the inelastic mean free path which scales as $\lambda \sim V_{T} / \log \left(V_{T}\right)$ for energies above the plasma excitation. ${ }^{25}$ Thus we find intensity $\sim \log \left(V_{T}\right) /\left(V_{T} \cdot \log \left(V_{T}\right)+V_{T}\right)^{2}$. This relationship is plotted in Fig. 2(b) with good agreement with experimental data. Despite this good agreement, there remains room for alternative explanations of the increase in efficiency with larger negative bias. In particular, we do not know the depth or spatial extent of the optically active sites and therefore cannot determine the extent to which the changing depth profile of the injected carriers affects the relevant interaction volume.

In summary, we have presented an investigation of optically active surface defects in sputtered AZO films using STM-CL. Topographic scans suggest that the optically active sites are distributed evenly across the surface at a density of $\sim 10^{10} \mathrm{~cm}^{-2}$. The observed deep-level emission peaks are unusually narrow, especially when compared to PL measurements, and fingerprint the electronic structure of the predominant near-surface optically active defect, which we propose is an oxygen vacancy. The observed increase in quantum efficiency with increasing bias is attributed to phonon-assisted de-trapping of holes trapped at $\mathrm{V}_{\mathrm{O}}^{\bullet \bullet}$ as predicted theoretically in Refs. 6-8.

This work was supported by NSF/NNIN through the use of their facilities at Harvard University's Center for Nanoscale Systems (CNS). E.M.L. acknowledges support from NSEC. R.J. acknowledges support from the Harvard University Center for the Environment. The authors are thankful for helpful discussions with E. Hu, D. Clarke, A. Magyar, A. Podpirka, R. J. Levine, and L. L. Considine.

${ }^{1}$ Y. C. Kong, D. P. Yu, B. Zhang, W. Fang, and S. Q. Feng, Appl. Phys. Lett. 78, 407 (2004).

${ }^{2}$ P. D. Yang, H. Q. Yan, S. Mao, R. Russo, J. Johnson, R. Saykally, N. Morris, J. Pham, R. R. He, and H. J. Choi, Adv. Funct. Mater. 12, 323 (2002).

${ }^{3}$ K. Watanabe, Y. Nakamura, M. Ichikawa, S. Kuboya, R. Katayama, and K. Onabe, J. Vac. Sci. Technol. B 27, 1874 (2009).

${ }^{4}$ D. D. D. Ma, S.-T. Lee, P. Mueller, and S. F. Alvarado, Nano Lett. 6, 926 (2006).

${ }^{5}$ D. M. Hofmann, D. Pfisterer, J. Sann, B. K. Meyer, R. Tena-Zaera, V. Munoz-Sanjose, T. Frank, and G. Pensl, Appl. Phys. A 88, 147 (2007).

${ }^{6}$ S. B. Zhang, S.-H. Wei, and A. Zunger, Phys. Rev. B 63, 075205 (2001).

${ }^{7}$ A. Janotti and C. G. V. de Walle, Appl. Phys. Lett. 87, 122102 (2005).

${ }^{8}$ F. Oba, A. Togo, I. Tanaka, J. Paier, and G. Kresse, Phys. Rev. B 77, 245202 (2008).

${ }^{9}$ A. Janotti and C. G. V. de Walle, Rep. Prog. Phys. 72, 126501 (2009).

${ }^{10}$ S. Tanuma, C. J. Powell, and D. R. Penn, Surf. Interface Anal. 11, 577 (1988).

${ }^{11}$ D. R. Penn, Phys. Rev. B 13, 5248 (1976).

${ }^{12}$ M. Dapor, Surf. Sci. 600, 4728 (2006).

${ }^{13}$ J. J. Quinn, Phys. Rev. 126, 1453 (1962).

${ }^{14}$ K.-K. Kim, H.-S. Kim, D.-K. Hwang, J.-H. Lim, and S.-J. Park, Appl. Phys. Lett. 83, 63 (2003).

${ }^{15}$ E. M. Likovich, R. Jaramillo, K. J. Russell, S. Ramanathan, and V. Narayanamurti, Phys. Rev. B 83, 075430 (2011).

${ }^{16}$ K. Vanheusden, W. L. Warren, C. H. Seager, D. R. Tallant, J. A. Voigt, and B. E. Gnade, J. Appl. Phys. 79, 7983 (1996).

${ }^{17}$ R. Das, K. Adhikary, and S. Ray, Jpn. J. Appl. Phys. 47, 1501 (2008).

${ }^{18}$ C. H. Ahn, Y. Y. Kim, D. C. Kim, S. K. Mohanta, and H. K. Cho, J. Appl. Phys. 105, 013502 (2009).

${ }^{19}$ L. S. Vlasenko and G. D. Watkins, Phys. Rev. B 71, 125210 (2005).

${ }^{20}$ Y.-H. Lin, C.-C. Lin, J.-M. Wu, U.-S. Chen, J.-R. Chen, and H. Shih, Thin Solid Films 517, 1225 (2008).

${ }^{21}$ K. I. Hagemark and P. E. Toren, J. Electrochem. Soc. 122, 992 (1975).

${ }^{22}$ K. Lott, S. Shinkarenko, T. Kirsanova, L. Turn, E. Gorohova, A. Grebennik, and A. Vishnjakov, Solid State Ionics 173, 29 (2004).

${ }^{23}$ G. D. Mahan, J. Appl. Phys. 54, 3825 (1983).

${ }^{24}$ R. H. Fowler and L. Nordheim, Proc. R. Soc. London 119, 173 (1928).

${ }^{25}$ R. A. Ferrell, Phys. Rev. 101, 554 (1956). 